\title{
Estrategias para la mejora de la accesibilidad a la Web y a sus contenidos
}

\author{
Esmeralda Serrano Mascaraque \\ Universidad de Alcalá de Henares (España)
}

\section{Resumen}

Se explican las principales estrategias que facilitan la creación de una web accesible y que un gestor de la información actual debe conocer. Suponen priorizar, si es necesario, el acceso al contenido por encima de la apariencia de las páginas. Se postula la accesibilidad web como una actividad prioritaria del profesional de la información e incluso como un nicho de actividad profesional.

Palabras clave: Accesibilidad web. Estrategias de accesibilidad web. Medios de comunicación. Gestor de la información. Diseño web accesible. Espacio web.

\section{Abstract}

The main strategies that facilitate the creation of an accessible web page are presented and analyzed. An information manager must be aware of the problem and the strategies and techniques available to overcome it. They presuppose prioritizing the content over the aesthetical aspects, if necessary. Web accessibility is postulated a as major activity for the information professional and even as a potential professional niche.

Keywords: Web accessibility. Web accessibility strategies. Mass media. Information manager. Accessible web design. Web space.

\section{Introducción}

El ser humano ha ido evolucionando en sus formas de comunicación (desde la escritura jeroglífica hasta la era digital con Internet, pasando por los grandes medios de comunicación de masas, tradicionalmente analógicos y ahora también digitales, como son la radio y la televisión) para satisfacer las necesidades informativas. Estos nuevos medios de comunicación han sido posibles gracias a los avances tecnológicos experimentados. Hoy en día es difícil imaginarse un mundo sin recursos tecnológicos; quizá las generaciones anteriores sean un poco reacias a su utilización directa, pero con certeza se benefician de las ventajas que las nuevas tecnologías han aportado a sus vidas (por ejemplo, de la posibilidad de elegir entre más de cincuenta canales de televisión o incluso de la programación "a la Scire. 15 : 2 (jul.-dic. 2009) 121-139. ISSN 1135-3716. 
carta" con la televisión digital, así como de comunicaciones más eficaces y con mayor calidad).

Es incuestionable el impacto que Internet ha tenido en los tradicionales medios de comunicación, y el planteamiento de nuevas formas de comunicación a través de las tecnologías de la información y la comunicación (TIC) obliga al profesional de la información a desenvolverse con soltura en estas nuevas tecnologías. Por ello estos expertos no pueden mantenerse al margen cuando absolutamente todos los medios de comunicación se abren a la Red universal. El profesional debe desempeñar un nuevo papel acorde con la sociedad de la información, Internet y el fenómeno de la globalización.

Esta nueva era digital propugna de entrada y por imposición legal — Ley 34/2002 de Servicios de la Sociedad de la Información y el Comercio Electrónico (LSSICE), Ley 56/2007 y Real Decreto 1494/2007— la obligación de hacer accesible toda la información contenida en las páginas web pertenecientes a organismos oficiales y en aquellas cuyo diseño o mantenimiento sean financiados con fondos públicos. Pero esta responsabilidad y obligación de difusión de la información electrónica lleva consigo el desarrollo de una infraestructura tecnológica adecuada.

Además, las telecomunicaciones, y en especial Internet, representan el más eficaz vehículo de transmisión e intercambio de información, de forma que su incorporación a la vida económica y social ofrece innumerables ventajas. Asimismo, el acceso a las TIC crea oportunidades para todos, pues supone una importante ayuda para que cualquier persona desarrolle sus posibilidades en las más diversas circunstancias a lo largo de su vida personal y profesional. Esta cualidad se acentúa en el caso de las personas con discapacidad, a las que permite, en mayor grado, participar e integrarse en el desarrollo de la sociedad. Sin embargo, el acceso universal a la información puede convertirse en una barrera más, y esta vez infranqueable, si Internet no es accesible. Es aquí donde el gestor de la información deberá desempeñar su nuevo rol mitigando las barreras de infraestructuras y de formatos inaccesibles que obstaculizan esta participación.

Las recomendaciones estratégicas que a continuación se presentan van encaminadas a la consecución de una gestión eficaz a favor del acceso a la Web y a sus contenidos, y son el fruto de años de bagaje en la gestión de la información web.

\section{Estrategias para la mejora de la accesibilidad}

Las técnicas para crear una plataforma web accesible están basadas en los métodos clásicos de diseño de páginas web, de modo que se han ideado nuevas estructuras para añadir unas características de accesibilidad no cuantificable a los métodos tradicionales. Estas estructuras afectan a un nivel mayor de abstracción que la mera implementación del código de marcado de la página.

Scire. 15 : 2 (jul.-dic. 2009) 121-139. ISSN 1135-3716. 
El diseño web accesible ha ideado nuevas soluciones para las necesidades de las personas con discapacidad. De la misma manera que en los edificios los recursos construidos para personas discapacitadas pueden ser de utilidad para los no discapacitados (por ejemplo, las rampas en vez de las tradicionales escaleras), los recursos exclusivos para la accesibilidad de páginas web pueden ser muy valiosos para personas que no necesitan estrictamente de una web accesible.

Estos recursos no forman parte de ninguna especificación de accesibilidad web, puesto que son estructuras de diseño, no de codificación (realizada por un programador), y requieren un planteamiento de la organización de la información adecuado realizado por un profesional de la información. En las siguientes secciones se expondrán recursos de interés para la accesibilidad web. Por su utilidad y relevancia, el gestor de la información debería conocerlos y exigir su aplicación en todas las páginas web, accesibles o no. Y son fruto de una dilatada experiencia en el desarrollo de plataformas web.

\subsection{Tamaño de los elementos de la página}

Una página web debe poseer un diseño flexible, capaz de adaptarse a los diferentes agentes de usuario y a las necesidades particulares de sus usuarios (incluyendo aquellos que posean algún tipo de discapacidad). La página ha de poder visualizarse tanto en un monitor de un ordenador personal (workstation) como en una PDA o dispositivo portátil, un teléfono móvil, etcétera.

Para conseguir este objetivo se ha de diseñar una página cuyo aspecto se pueda adaptar a diferentes tamaños sin variar su esquema de organizar la información; es lo que se conoce en el mundo del diseño web como diseño elástico, ideado por Patrick Griffiths (2004). La elasticidad de un diseño web está destinada a facilitar la accesibilidad a aquellos usuarios que utilicen dispositivos especiales o que tengan problemas de visión tales como vista cansada, visión borrosa u otros tipos de deficiencias, pero nunca a personas con pérdida total de visión.

Una web elástica permite que el usuario personalice el tamaño de la página aumentando o disminuyendo las dimensiones de sus elementos (como una herramienta de zoom o lupa) para facilitar la visualización de los contenidos de las páginas. Es evidente que una persona con problemas de visión (vista cansada, miopía, etcétera) obtendrá grandes beneficios si puede aumentar el tamaño no solo de las fuentes de la pantalla, sino de todos los elementos.

La técnica seleccionada hace posible adaptar todos los elementos de la página de la siguiente manera:

- Los tamaños de las fuentes aumentan o disminuyen en función del factor de escala. Su aspecto no se deforma debido a que son elementos vectoriales, no mapas de bits. 
- Las capas y secciones aumentan o disminuyen sus dimensiones en la misma proporción que lo hacen las fuentes. Su aspecto no se deforma debido a su carácter vectorial.

— Las imágenes de tipo raster (no vectoriales) también cambiarán de tamaño, pero en ellas se apreciará un efecto de pixelado; este no debería afectar a la visualización de la información de la página: únicamente resultará menos atractiva. Sin embargo, en aquellos casos en los que la imagen posea una alta resolución o el navegador disponga de rutinas de escalado de alta calidad se mejorará la visualización de la misma.

- Las imágenes y elementos vectoriales, como las animaciones flash, cambiarán de tamaño del mismo modo que lo hacen las capas y las secciones, sin experimentar ninguna pérdida de calidad.

En la actualidad, algunos navegadores soportan esta funcionalidad de cambio de tamaño con independencia de la forma en que se haya implementado la página; por ejemplo, Opera u otros programas de asistencia, tomando el control de la parte de visualización del sistema operativo, aumentan el tamaño de la pantalla y consiguen este efecto, como ZoomText. Sin embargo, mediante un correcto diseño de la página se puede conseguir la misma funcionalidad que presentan estos costosos programas. Además, decantarse por la implementación de esta posibilidad de cambio de tamaño en el diseño de la página reportará muchos beneficios aparte del meramente económico, como apunta el Consorcio World Wide Web (W3C).

La técnica para lograr una web elástica se basa en la separación entre los contenidos y la representación, de manera que la maquetación se ha de realizar preferentemente por medio de capas < div $>$, que son dotadas de sentido gráfico en los estilos de las hojas CSS. De igual manera se podría proceder con la maquetación en tablas, pero esta podría presentar problemas a la hora de realizar ajustes; además, se obtendría una web elástica, pero no accesible.

A la hora de definir los tamaños de fuentes, capas <div>, imágenes y elementos auxiliares, se ha de emplear una medida "elástica"; es en esta característica donde reside la responsabilidad de que la página tenga un diseño elástico. La medida elástica a utilizar será em, que indica el porcentaje respecto a la fuente por defecto que tenga activada el agente de usuario; 1 em indica un tamaño del 100\% (igual) de la medida de la fuente activa en el agente de usuario; $1,5 \mathrm{em}$, un tamaño del $150 \%$, y así sucesivamente.

Para realizar la medida se toma como base la fuente por defecto que tenga activada en ese momento el navegador; por este motivo, no es una medida absoluta sino relativa. Basta con variar el tamaño de la fuente del navegador para que todos los elementos de la página que tengan medidas relativas con em cambien de tamaño al unísono y tomen una apariencia similar a la original, pero con otra escala. 
A pesar de que la medida em se basa en medidas de caracteres, se puede aplicar a los tamaños de todos los elementos de la página, como la longitud y la anchura de las capas < div $>$, las imágenes, las animaciones flash, etcétera. Como se trata de una medida proporcional, que afecta a todos los elementos, al cambiar la base cambiarán todos al mismo tiempo.

La aplicación de esta medida al código XHTML de marcado no representará mayor complicación si se usan los principios preconizados por el Consorcio World Wide Web (W3C): separación total de información (XHTML) y apariencia (CSS). Las medidas únicamente aparecerán definidas dentro de la hoja de estilos y en el código XHTML.

En el código de la figura 1 se muestra la utilización de medidas em para la definición de algunas capas.

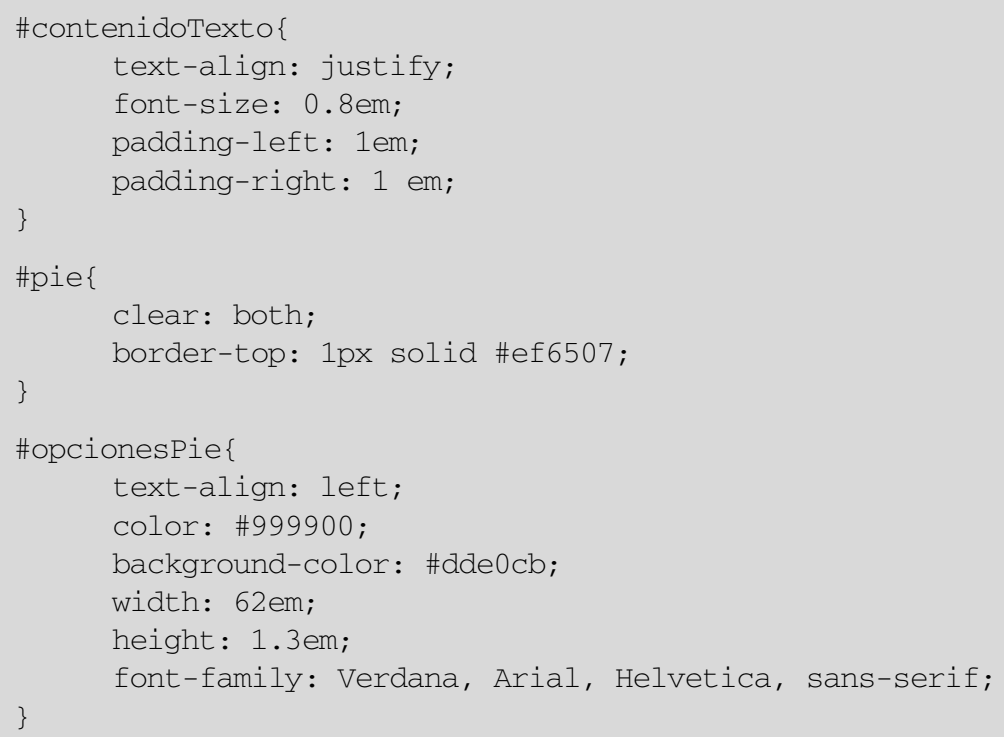

Figura 1. Utilización de medidas em.

Cuando se trabaja con medidas relativas no existe una traslación directa entre el número de em que ocupa una capa y el número de píxeles que la representan en la pantalla; este hecho, unido a su cualidad hereditaria, puede dificultar el diseño con este tipo de medida.

Scire. 15 : 2 (jul.-dic. 2009) 121-139. ISSN 1135-3716. 
Finalmente, debe especificarse el tamaño de la fuente por defecto para toda la página, puesto que existen navegadores, como Internet Explorer 6, que no visualizan el tamaño indicado si antes no se consigna explícitamente el valor inicial.

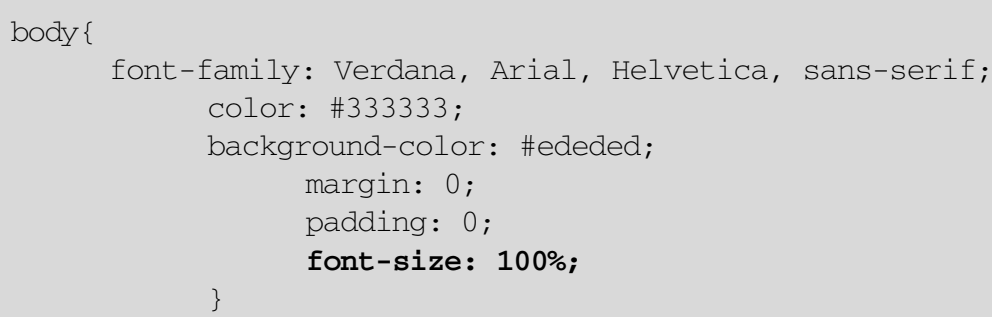

Figura 2. Consignación valor inicial de la fuente.

\subsection{Hojas de estilo alternativas de alto contraste}

Cuando se ha realizado correctamente el desarrollo de una página web siguiendo los estándares marcados por el W3C, en especial la separación del código de la apariencia y la norma UNE 139803, es sencillo conseguir que tenga diferentes apariencias con poco esfuerzo.

Una de las utilidades del intercambio de hojas de estilo, además de la atracción visual que puede provocar en el usuario y de las posibilidades de personalización que permite, es crear apariencias específicas para personas con deficiencias visuales. De este modo, se puede crear una apariencia de alto contraste específica para mejorar la accesibilidad o simplemente hacer más cómoda la lectura, obviando la apariencia visual.

El paso de una apariencia normal a una de alto contraste consiste simplemente en cambiar las hojas de estilo de la página web por otras especiales para usuarios con problemas de visión.

Este efecto de alto contraste se consigue simplemente cambiando las referencias de los archivos de hojas de estilo a otros archivos equivalentes con los colores modificados. Estos archivos acaban con la terminación AC.

$<$ link rel="stylesheet" type="text/css"

href="include/CSS/estilos_2006AC.CSS" />

Figura 3. Fragmento de código de una apariencia normal.

Scire. 15 : 2 (jul.-dic. 2009) 121-139. ISSN 1135-3716. 
$<$ link rel="stylesheet" type="text/css"

href="include/CSS/estilos_2006AC.CSS" />

Figura 4. Fragmento de código de una apariencia de alto contraste.

Para facilitar la creación de las hojas de estilo de alto contraste se puede partir de las de apariencia normal y cambiar solamente algunas de las propiedades de los estilos (las que afectan al color). A continuación se citan unas sencillas reglas extraídas de la experiencia diaria de trabajar con discapacitados visuales (1).

- El color de fondo deberá ser negro y deberá predominar en el segundo plano.

- El color del texto y de los elementos estructurales ha de ser blanco, siempre que estos estén en primer plano y sean de relevancia.

- El color del fondo de los enlaces será fucsia, y el texto, negro. Además, cuando el cursor pase por encima de ellos, estos deberán cambiar a fondo blanco y texto negro.

- El color del borde de los enlaces no textuales, como enlaces en imagen, será fucsia y cambiará a blanco cuando el foco pase por ellos.

- El color del fondo de los enlaces especiales será verde, y el texto, negro. Además, cuando el cursor pase por encima de ellos deberán cambiar a fondo blanco y texto negro.

- Todo elemento que se encuentre en segundo plano y que no sea relevante (por ejemplo, las imágenes de fondo de capas) deberá ser eliminado.

Estas reglas son fruto de la experiencia realizada con los colores básicos de alto contraste. No obstante, será necesario utilizar un programa de validación de colores, como puede ser aDesigner (2), que se encargue de evaluar la calidad de la página en cuanto a la separación de los colores.

De esta manera, y con un coste mínimo, se puede transformar una hoja de estilo que no es de alto contraste en una adecuada para personas con problemas de visión, lo que, unido a la posibilidad de variar el tamaño de la página web con las medidas relativas, hace que el usuario pueda personalizar totalmente la interfaz para adaptarla a sus necesidades particulares (incluyendo sus deficiencias físicas o técnicas), ahorrando así el coste de programas externos a los agentes de usuario que realizan este tipo de transformaciones.

\subsection{Contenidos y elementos de navegación ocultos}

Los enlaces de navegación y contenidos ocultos pretenden facilitar el acceso a la información a las personas con discapacidad, expresando de un modo textual aquella información que las personas videntes pueden obtener por el contexto gráfico.

Scire. $15: 2$ (jul.-dic. 2009) 121-139. ISSN 1135-3716. 
La información que se puede obtener del contexto es la que se deduce de la disposición de los recursos gráficos, como pueden ser la separación de secciones, la organización en columnas, la disposición de los elementos de una tabla, etcétera. Esta información es captada visualmente por el usuario sin discapacidad visual y le orienta acerca sobre cómo utilizarla; cuando un usuario observa un menú de opciones, aunque no se detenga a leer cada una de ellas, puede obtener la información global de su número aproximado y de si están organizadas de alguna manera. Esta información es imperceptible para una persona invidente o que necesite de sistemas de asistencia de sintetización de voz.

La solución para paliar esta desventaja de las personas invidentes consiste en utilizar los recursos (X)HTML para dotar a la página de metainformación que ayude al usuario con discapacidad visual a comprender la estructura de la página, sin por ello perjudicar la apariencia visual de la misma o sobrecargar de información a los usuarios videntes, ya que la información con carácter redundante no les será mostrada.

Las hojas de estilo permiten "ocultar" determinada información, principalmente textual, de la visualización de la página; sin embargo, dicha infromación formará parte del código, de manera que, si no se utilizan las hojas de estilo, los contenidos aparecerán en el lugar indicado.

Este resultado se logra a través de la utilización de efectos de hojas de estilo (CSS). Se ha de crear un estilo específico para estos casos, que puede tener como nombre oculto, que haga desaparecer el texto, bien mediante la propiedad display: hidden o trasladándolo a un lugar de la pantalla (por ejemplo, a unas coordenadas negativas) donde no aparecerá nunca.

Esta última alternativa surgió para solventar la incompatibilidad de Internet Explorer y JAWS (software de asistencia con sintetizador de voz comúnmente utilizado por la comunidad de invidentes) con la propiedad display: hidden, aunque es previsible que en próximas versiones esta propiedad funcione correctamente en ambos, puesto que forma parte del estándar del W3C para definir las hojas de estilo.

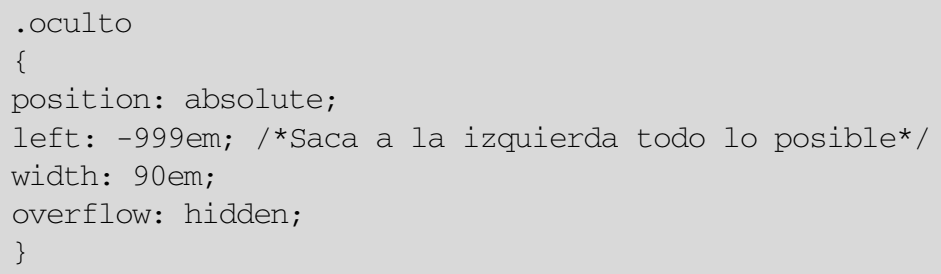

Figura 5. Fragmento de hoja de estilo de definición de estilo oculto, sin emplear la propiedad display: hidden. 
Los contenidos ocultos se pueden utilizar en multitud de ocasiones, como en explicaciones, enlaces internos o informaciones puntuales para personas con discapacidad.

\subsubsection{Explicación del contenido}

Los mensajes ocultos se utilizan con frecuencia cuando se cree relevante advertir sobre el contexto del contenido que aparece a continuación. Por ejemplo, si existe un pie de página en un documento HTML, este aparecerá en un tipo de letra menor que el texto principal, circunstancia que pasará desapercibida para un invidente. Para expresar que el contenido que aparece a continuación de la aclaración es un pie de página se puede indicar con un texto oculto. No obstante, no se debe abusar de este recurso, puesto que puede ralentizar la navegación por la página.

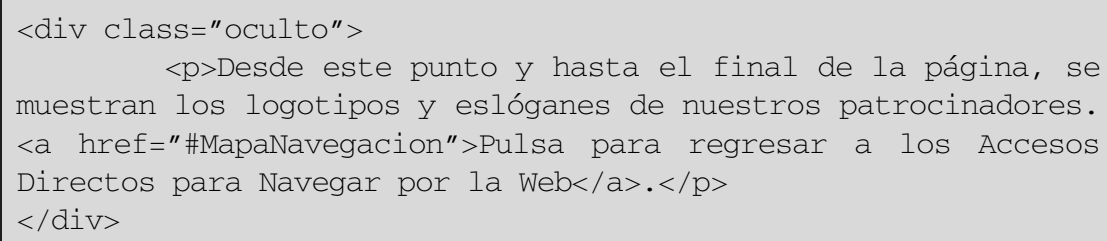

Figura 6. Fragmento de código para aclarar el contenido de un pie de página.

\subsubsection{Enlaces internos}

Para comprender la utilidad de los enlaces internos hay que recordar que los sistemas de asistencia al acceso a la información, que utilizan sintetizadores de voz o traducen a braille los contenidos, obligan a un acceso secuencial de los contenidos. Cada una de las palabras que transcriben tiene un orden, por lo que no se puede acceder a un contenido sin haber visitado los anteriores.

Las personas que no necesiten emplear programas de asistencia podrán pasar de una sección a otra y comprender rápidamente la estructura de la web: dónde está el menú, dónde el contenido, el pie de página, etcétera. Si quieren saltar del comienzo del contenido al pie de la página, solo tendrán que dirigir la mirada al lugar deseado y seleccionarlo con el puntero del ratón, lo que no les supondrá un excesivo esfuerzo.

Con el fin de intentar modelar este sistema de acceso aleatorio a la información en las páginas web accesibles (aleatorio considerando que cuesta el mismo esfuerzo saltar a cualquier zona de la web) se pueden utilizar unos enlaces internos para el salto entre secciones que, aunque no permitan la misma agilidad que Scire. 15 : 2 (jul.-dic. 2009) 121-139. ISSN 1135-3716. 
tienen las personas sin problemas de visión, sí facilitan el proceso de navegación para aquellas otras con dificultades moderadas o graves.

La técnica consiste en insertar enlaces desde y hacia cada una de las secciones importantes de la página. Para facilitar su utilización se colocará al comienzo de la página un menú de enlaces oculto o menú de navegación que dirigirá a cada uno de los elementos de la lista seleccionados para que aparezcan en dicho menú de navegación.

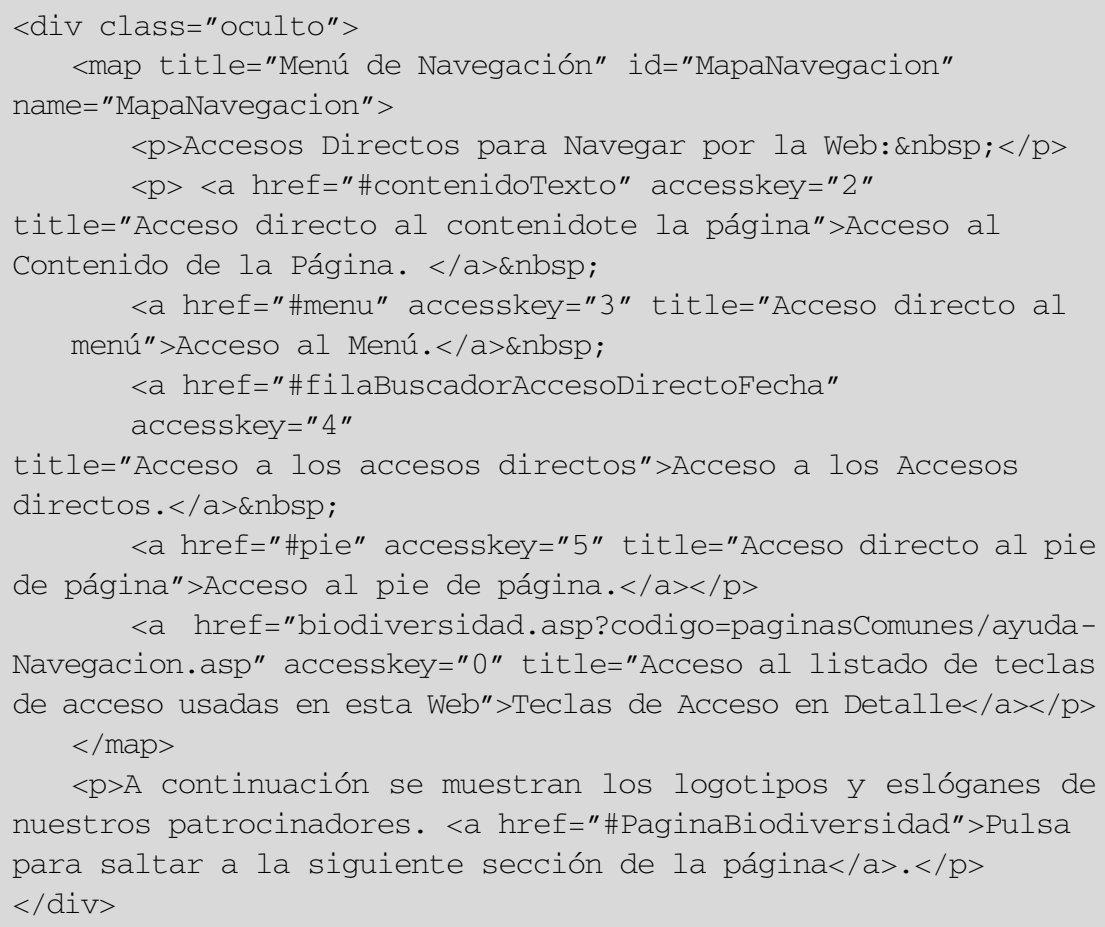

Figura 7. Código fuente de un prototipo de menú de navegación.

Como se aprecia en el código fuente de la figura 7, se utiliza un mapa de enlaces que dirige el foco de la página a las secciones relevantes. Cada uno de los enlaces dispone de una tecla de acceso directo asignada, lo que facilitará su activación sin que el foco de navegación esté situado sobre el mismo. El destino de los enlaces se corresponde con el atributo $i d$ de las capas que contienen el destino del enlace. 
Si visualizásemos la página con un navegador en modo texto que no haga uso de las hojas de estilo, se observaría cómo sí aparece el menú de navegación; sin embargo, en un navegador visual como Mozilla Firefox, la apariencia de la página no se vería afectada.

El menú de opciones de las páginas suele estar dividido en diferentes secciones, cada una de ellas con un número variable de opciones. Es interesante que el usuario pueda saltar de unas secciones a otras: cuando quiera buscar un enlace saltará a la sección adecuada en la que se encuentre el grupo de enlaces al que pertenece el buscado y a continuación accederá a él de forma secuencial.

Como se puede observar en la figura 8 , cada una de las secciones en las que se divide el menú cuenta con un enlace a la siguiente sección cuyo identificador

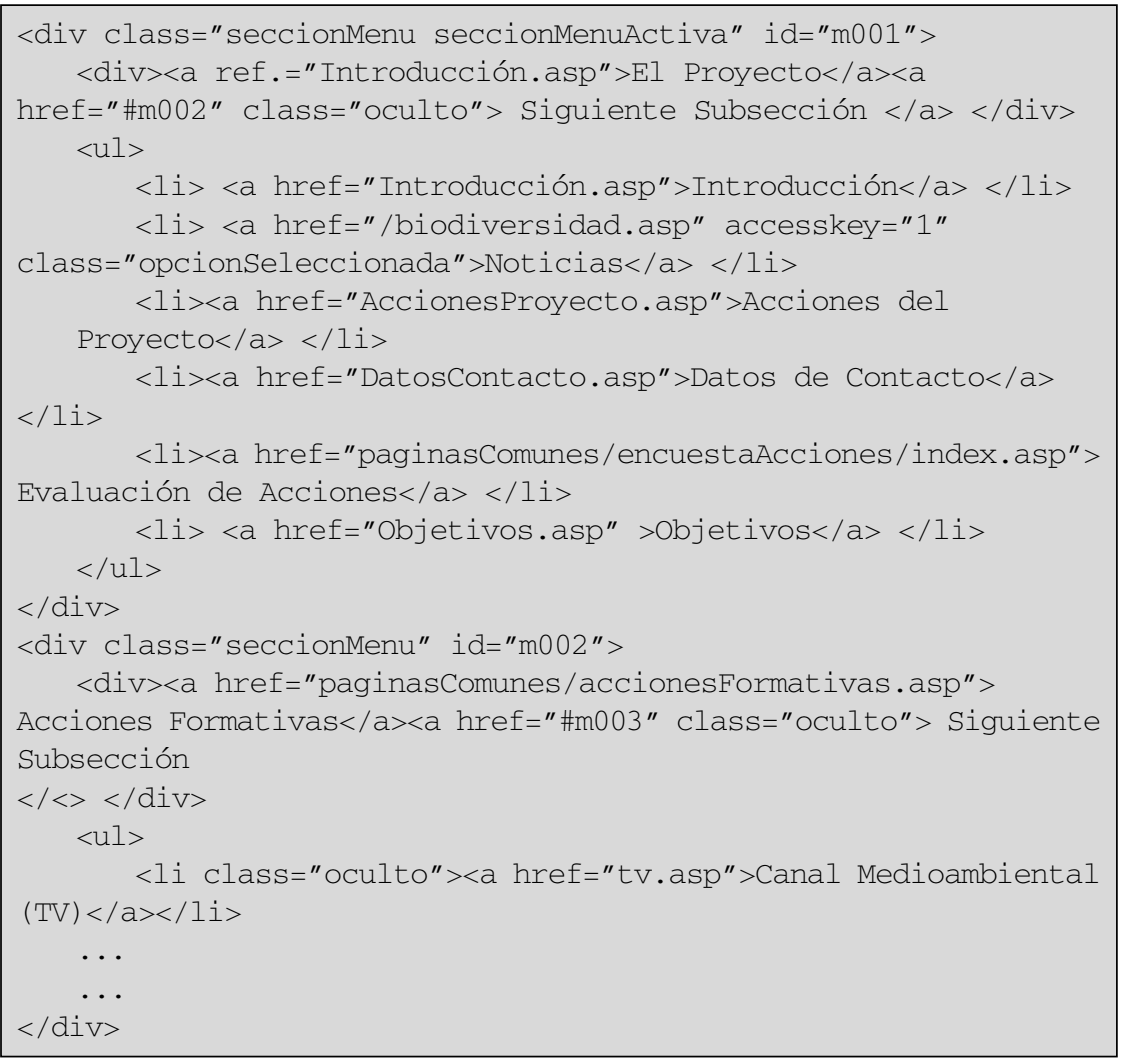

Figura 8. Código fuente donde se muestra cómo están estructuradas de las capas del menú de opciones, con los enlaces a continuación de cada elemento.

Scire. 15 : 2 (jul.-dic. 2009) 121-139. ISSN 1135-3716. 
ha sido asignado de forma consecutiva. Al igual que sucede con el resto de elementos ocultos, no se visualizará en la versión gráfica, pero sí en la que utilizan los programas de asistencia.

Al final de cada una de las secciones relevantes de la página existirá un enlace para regresar directamente al menú de navegación; gracias a este enlace el usuario puede saltar a otras secciones o simplemente avanzar de forma secuencial, como en una página web normal.

\subsubsection{Información específica para personas con discapacidad}

Los mensajes ocultos también pueden utilizarse para transmitir a los usuarios que sí perciben estos datos alguna información de utilidad referida a los sistemas de asistencia que utilizan. Por ejemplo, para modificar las características de la sintetización de voz, para alertarles de la aparación de una serie de caracteres no habituales o, simplemente, dar instrucciones sobre cómo acceder a la información con los programas que utilizan.

\subsection{Formato de contenido texto plano}

Aunque no se trata de un requisito indicado en las recomendaciones de accesibilidad, desde el punto de vista práctico puede ser útil para las personas invidentes el hecho de disponer de una versión de los contenidos en texto plano, aunque estos estén en modo accesible de HTML.

Los invidentes están acostumbrados a utilizar otros sistemas para acceder a la información, como documentos en braille o sintetizadores de voz. Pero para permitir el acceso a Internet a este colectivo ha sido necesario adaptar e implementar nuevas fórmulas alternativas de acceso como son los programas y dispositivos de asistencia. Estos dispositivos de ayuda deben adaptarse a la forma de trabajar de las personas discapacitadas para reducir las dificultades de acceso a la información de Internet en función del tipo de discapacidad de cada individuo.

Los programas de asistencia mediante sintetización de voz son válidos para navegar por Internet, ya que el propio acto de navegar por las páginas ayuda a concentrar la atención. No ocurre lo mismo cuando se escucha la narración de un texto excesivamente largo; a una persona invidente o con problemas de visión graves puede resultarle tedioso o cansado escuchar durante largo rato a un sistema de sintetización de voz, aun cuando, debido a su deficiencia, presente una capacidad auditiva altamente desarrollada. Para evitar esto, la alternativa que les resta es la lectura del texto en líneas braille mediante el tacto.

Una línea braille es un dispositivo conectado al ordenador que es capaz de modelar los relieves de las letras de las frases que se le indiquen mediante un programa, de modo que se puede tomar un texto y transformarlo en braille gracias a esta línea. El software que hace de interfaz con la línea braille necesita un formato de texto 
determinado (.bra), que es proporcionado por programas especializados como, por ejemplo, CobraWin. Este tipo de programas necesitan partir de un archivo en formato RTF o texto plano para realizar las transformaciones correctas a archivos .bra. Los invidentes que desean trasladar una información desde web hasta la línea braille utilizan algunas estrategias, como transformarla con algún editor de texto y retocarla manualmente; para ello, los más aventajados en conocimientos de informática utilizan a menudo programas que no son accesibles y que, en el mejor de los casos, motivan que los resultados no cubran sus expectativas.

Por lo tanto, sería conveniente proveer la información disponible en formato HTML accesible, que debería ser toda, en formato de texto plano .txt sin las etiquetas, solo el contenido. Se trata de un proceso sencillo y automatizable a partir de la conversión de los contenidos a formato HTML accesible. Para ello únicamente han de seguirse las siguientes reglas:

- Los títulos H1, H2... han de estar numerados en forma de esquema; es decir, para un nivel 2 habrá dos números (X.X), tres para un nivel 3, y así sucesivamente.

— Las listas numeradas también deben numerarse de forma explícita.

- Para las listas sin numerar puede emplearse algún carácter como un asterisco o un guión, seguido de un punto.

— La separación entre párrafos y elementos debe ser de al menos una línea en blanco.

- Se ha de proporcionar una información equivalente a toda aquella que aproveche el código de marcado HTML, insertando texto explicativo si fuera necesario como introducción a tablas o listas.

Estos archivos de texto se pondrán a disposición de los usuarios como una versión más de los contenidos en otro formato, para que la información esté accesible en su modo más básico con el fin de que pueda ser manipulada por los usuarios para adaptarla a sus necesidades.

\subsection{Generación de los contenidos en formato audio}

Las personas discapacitadas con problemas de visión utilizan sistemas de asistencia para navegar por Internet, los cuales consisten normalmente en sintetizadores de voz que leen la información textual que aparece en pantalla. Esta clase de programas de asistencia suelen ser caros y de uso personal, por lo que quizá haya usuarios que los necesiten y no dispongan de ellos. Adicionalmente, otros usuarios con problemas leves de visión, a los que no les resultan imprescindibles los programas de asistencia de sintetización de voz, agradecerían disponer de estos o de otros medios para acceder con mayor facilidad a la lectura de la información.

Scire. 15 : 2 (jul.-dic. 2009) 121-139. ISSN 1135-3716. 
Los enormes avances que se están sucediendo en el ámbito de las nuevas tecnologías de la comunicación hacen posible actualmente diversificar los medios para la divulgación de la información, fomentando la accesibilidad de la misma. Entre esas vías novedosas de obtener información destaca la posibilidad de ofrecer la información web en un soporte que permite al usuario no solo optar entre los contenidos disponibles que desea escuchar, sino también decidir el momento, e incluso el lugar, en que desea escucharlos.

Por consiguiente, el objetivo será que los documentos que se publiquen en la plataforma web sean accesibles en formato audio. Se trata de una técnica que se aplica a los sistemas de sindicación de noticias (RSS) de manera se transforman en audio, normalmente comprimido en MP3 u otro formato semejante, y que origina el fenómeno denominado podcasting (término acuñado por la tendencia creada por el reproductor iPod de Apple). De este modo, no solo se beneficia a las personas con discapacidad visual, sino que se ayuda con un nuevo modo de comunicación a facilitar el acceso a los contenidos a aquellas personas que lo necesiten.

El archivo de texto plano que se puede utilizar como base para la transformación automática a formato de audio es el mismo que se genera para la conversión a formato braille, tal y como se ha explicado en la sección anterior. Este formato de texto plano es el ideal, puesto que se explican todos aquellos artificios que no son textuales, como por ejemplo los elementos de separación de listas, y por lo tanto en la versión audible también quedarán perfectamente explicados.

Una vez se tengan los archivos en formato MP3 se incluirán en cada uno de los contenidos, preferentemente justo antes de estos, en un enlace lo suficientemente descriptivo y representativo para que las personas con deficiencias visuales puedan acceder a este formato.

\subsection{Teclas de acceso directo}

Las teclas de acceso directo permiten acceder a unos enlaces o secciones determinados de la página mediante la ejecución de combinaciones de teclas o de un dispositivo equivalente. Son especialmente útiles para personas con discapacidad motora, ya que reducen la cantidad de instrucciones que tienen que transmitir a su interfaz para poder moverse por la página web.

Las teclas de acceso directo que se han de emplear dependen de la configuración del agente de usuario. Estas son las combinaciones utilizadas en los navegadores más habituales:

Internet Explorer: ALT + número, y posteriormente ENTER

Netscape: ALT + número

Mozilla: ALT + número

FireFox: ALT + número

Opera: MAYÚSCULAS + ESC + número

Scire. 15 : 2 (jul.-dic. 2009) 121-139. ISSN 1135-3716. 
Las teclas de acceso directo disponibles son escasas debido a que muchas combinaciones están reservadas por el sistema operativo o por la propia interfaz del agente de usuario; por ello, generalmente se acude al uso de los diez primeros números.

No existe una norma que regule la asignación de las teclas de acceso rápido a unas secciones determinadas, pero se suelen asignar las que a continuación se enumeran:

1: Página de Inicio o Home Page.

2: Contenido, que muestra la información relativa a la opción elegida.

3: Menú de navegación, dispuesto en la parte izquierda de la pantalla y que permite navegar por las secciones del portal.

4: Búsqueda.

5: Pie de página, desde donde se puede acceder al mapa web.

6: Mapa web, en el que se muestran todas las secciones del portal.

7: Aviso legal.

8: Opción de mandar un correo electrónico al administrador del sitio web.

0: Ayuda sobre las operaciones que se pueden hacer con las teclas rápidas.

Para poder usar otras combinaciones de teclas se pueden emplear funciones codificadas en lenguaje JavaScript. Las reglas de accesibilidad prohíben el uso de lenguajes de script siempre que exista pérdida de alguna funcionalidad esencial, pero las teclas de acceso rápido no suponen una merma en la percepción de la información; más bien todo lo contrario: constituyen una mejora, aunque no imprescindible, motivo por el cual sí se permite su utilización.

\subsection{Mapa web}

El mapa web consiste en un listado de hipervínculos de todas las secciones de las que consta la plataforma web en forma de lista jerárquica. Permite delimitar las funciones que se pueden llevar a cabo en forma de resumen.

La accesibilidad de los mapas web viene dada por la estructura jerárquica en la que deberían estar dispuestos. Existen muchas formas de especificar un mapa web: mediante imágenes, animaciones, estructuras circulares, columnas, etcétera, pero, desde el punto de vista de la accesibilidad, la forma más adecuada es la creación de una lista jerárquica de enlaces a las diferentes secciones relevantes de la página. Sin embargo, a semejanza de lo que ocurre en la praxis empleada para la construcción de listas anidadas de elementos, no conviene que exista una jerarquía excesivamente profunda para no despistar al usuario.

En el código fuente de la figura 9 puede observarse una estructura correcta de listas jerárquicas utilizada en la elaboración de un mapa web. 


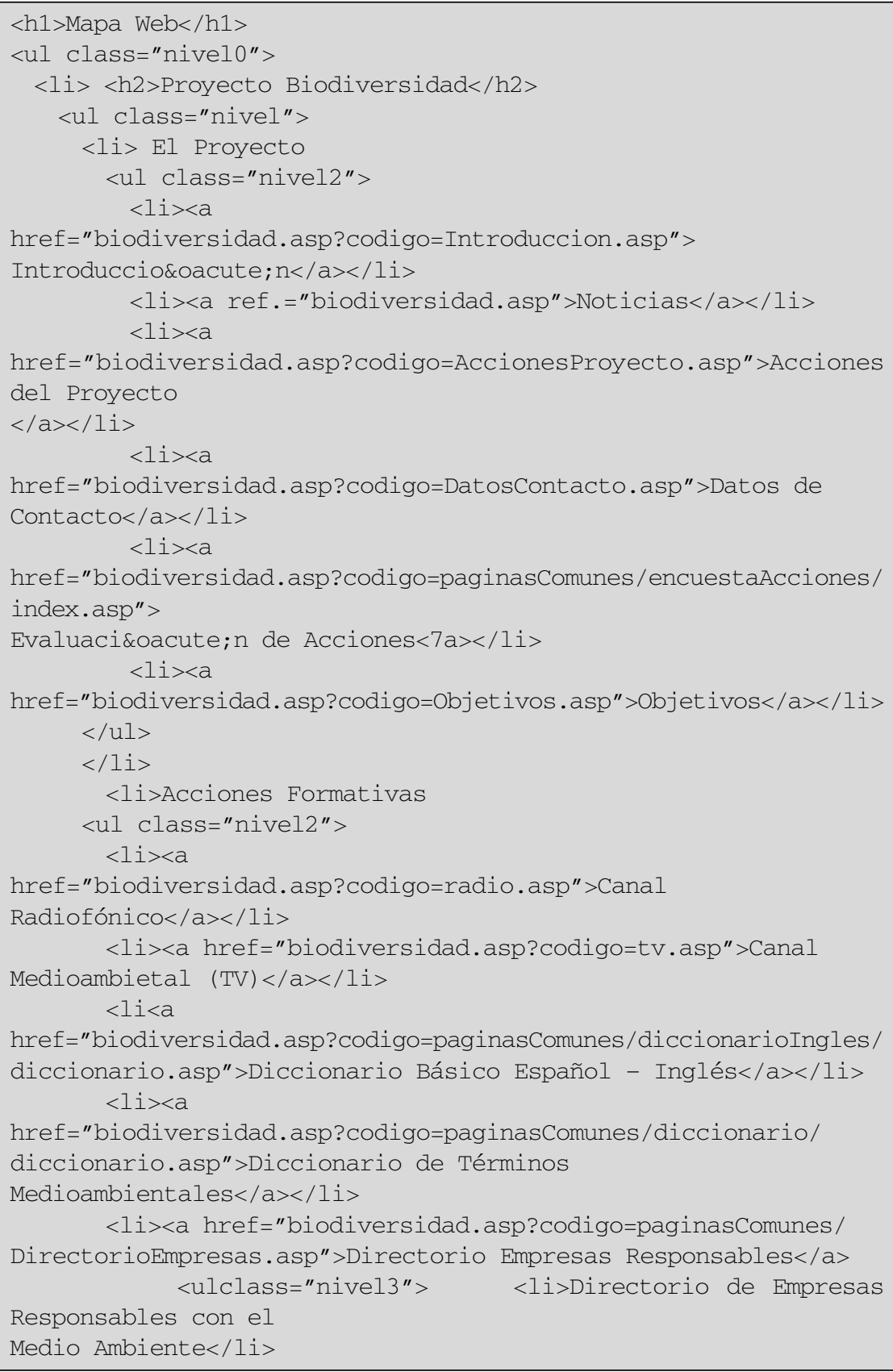




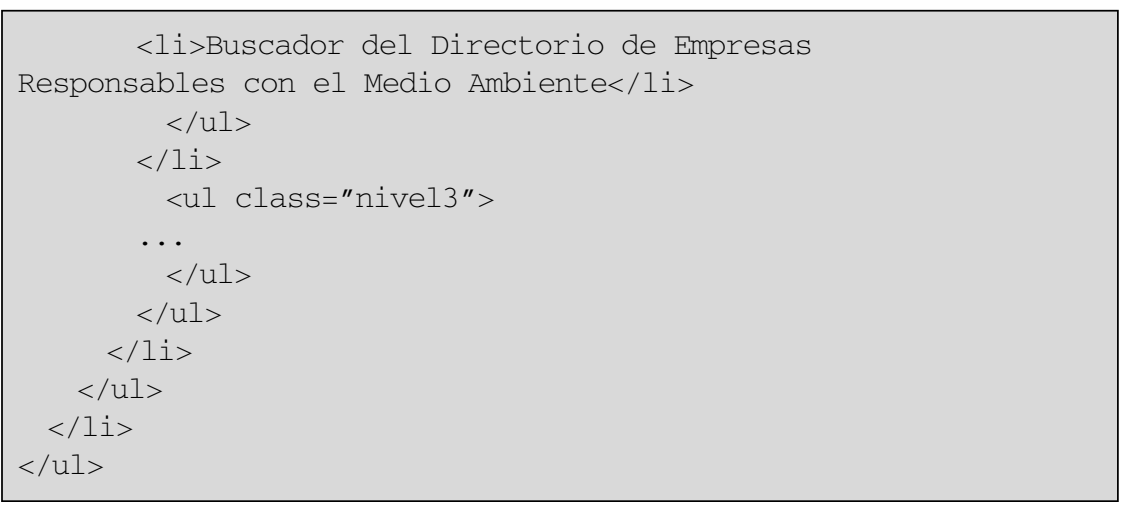

Figura 9. Código fuente de las listas jerárquicas empleadas en un mapa Web.

\section{Conclusiones}

La adaptación a la versión accesible de una plataforma web que explícitamente no lo sea pero que se rija por los estándares de diseño indicados por el W3C representará un coste ínfimo. Será necesario instruir en accesibilidad a los diseñadores web, y sobre todo concienciarlos de la importancia que esta reviste de cara a la consecución del acceso universal a la información, derecho que asiste a todo ciudadano. Si el proceso de accesibilidad se realiza desde el comienzo, es decir, desde la concepción del diseño, será más liviano y menos gravoso. Además, el gasto mínimo realizado puede considerarse como una inversión de futuro si se tienen en cuenta las consecuencias derivadas: mejora el posicionamiento en los buscadores, aumenta el número de usuarios que pueden acceder a la información, mejora la imagen de la web al preocuparse por temas sociales, etcétera.

El aspecto comercial, hasta el momento, ha entorpecido la consecución plena de la accesibilidad web, puesto que se ha ejercido la praxis errónea y generalizada por parte de los diseñadores de relegar a un segundo plano el contenido de las páginas web por la primacía de la apariencia. Esta praxis debe erradicarse; en los contenidos se ha de prestar más atención a estructurar correctamente la información (en ella debería intervenir forzosamente un gestor de la documentación) que a crear una apariencia deslumbrante. Pero la situación está empezando a cambiar, puesto que el sector comercial ha comenzado a vislumbrar un canal de negocio en la accesibilidad web.

Por último, hay que recalcar que el canal de comunicación actual es por antonomasia la Web; por ello los profesionales de la documentación deben canalizar su esfuerzo para mejorar la accesibilidad de las páginas web y los contenidos

Scire. 15 : 2 (jul.-dic. 2009) 121-139. ISSN 1135-3716. 
albergados en ellas. Pese a que el presente no es muy alentador, puede atisbarse un futuro prometedor respecto a la expansión y generalización del acceso a la información universal (con independencia de cualquier limitación física o técnica), similar a lo experimentado con la introducción de Internet; todo esto impulsado por el imperativo legal impuesto, por la concienciación social de la problemática existente y gracias a iniciativas como esta.

\section{Notas}

(1) Durante seis años coordiné un proyecto web de sensibilización medioambiental cuyas actividades (cursos, seminarios, concursos, etcétera) iban encaminadas a sensibilizar al colectivo de profesionales autónomos y PYME, con especial incidencia en el colectivo de discapacitados visuales (www.biodiversidad.fgua.es). Todo el trabajo volcado en este artículo es fruto de esa experiencia.

(2) aDesigner es un producto de IBM que simula las condiciones en las que navega por una web una persona que tiene algún tipo de discapacidad visual, de modo que permite comprobar la accesibilidad y la usabilidad de las páginas para una mayor variedad de usuarios que los sistemas de solo texto o de síntesis de voz. Se puede obtener de forma gratuita en http://www.alphaworks.ibm.com/tech/aDesigner.

\section{Referencias}

Actas de las I Jornadas Científico-Técnicas en Servicios Web (JSWEB’2005) (Granada, 2005). Madrid: Thomson-Paraninfo, 2005.

AENOR (2004). Norma UNE 139803: 2004. Aplicaciones informáticas para personas con discapacidad: requisitos de accesibilidad para contenidos en la Web. Madrid: AENOR, 2004.

Discapnet: Portal de las personas con discapacidad. http://www.discapnet.es/(2007-03-23). Griffiths, Patrick. Elastic design (2004). http://www.alistapart.com/articles/elastic (2007-12-27).

Griffiths, Patrick (2005). Elastic lawn CSS zen garden. http://www.csszengarden.com/?cssfile $=063 / 063$.css $(2007-12-27)$.

Ley 34/2002, de 11 de julio, de Servicios de la Sociedad de la Información y de Comercio Electrónico (LSSICE). // BOE n. ${ }^{\circ} 166$, de 12 de julio de 2002. Corrección de errores BOE n. ${ }^{\circ} 187$, de 6 de noviembre de 2002.

Ley 56/2007, de 28 de diciembre, de Medidas de Impulso de la Sociedad de la Información. // BOE n. ${ }^{\circ} 312$, de 29 de diciembre de 2007.

Real Decreto 1494/2007, de 12 de noviembre de 2007, por el que se aprueba el reglamento sobre las condiciones básicas para el acceso de las personas con discapacidad, a las tecnologías, productos y servicios relacionados con la sociedad de la información y medios de comunicación social. // BOE n. ${ }^{\circ} 279$, de 21 de noviembre de 2007.

Recursos para desarrolladores y/o diseñadores. http://www.technosite.es/recursos.asp (200803-27).

Sánchez, F.; Macías, M.; Lozano, M. (2003). Uso de ontologías en páginas web para mejorar su accesibilidad a invidentes. // VIII Jornadas de Ingeniería del Software y Bases

Scire. 15 : 2 (jul.-dic. 2009) 121-139. ISSN 1135-3716. 
de Datos: actas (JISBD’03) (Alicante, 2003). Alicante: Universidad de Alicante, 2003. 625-634.

Sidar (2007). Lista en castellano sobre problemas y soluciones de diseño accesible para la Red. http://es.groups.yahoo.com/group/accesoweb (2007-12-30).

Villa, Luis (2006). La importancia creciente de la accesibilidad de sitios web. http://ww.alzado. org/ articulo.php?id_art=2 (2008-12-23).

World Wide Web Consortium. Authoring tool accessibility guidelines 1.0. http://www.w3.org/ TR/WAI-AUTOOLS/ (2008-12-14).

World Wide Web Consortium (2001). Diseño accesible de páginas web: pautas de accesibilidad al contenido en la Web 1.0. Murcia: Dirección General de Política Social, 2001.

World Wide Web Consortium (2003). Documentos para el diseño accesible de contenidos en Web. [Madrid: Escuela Libre de Derecho y Economía, 2003].

World Wide Web Consortium (2005). Guías breves de tecnologías W3C. Gijón: Oficina Española, 2005.

World Wide Web Consortium. Web Accesibility Initiative (WAI). Beneficios auxiliares del diseño web accesible. http://ww.w3.org/2003/ 11/benefits-es.html (2009-03-20).

World Wide Web Consortium. Web Accessibility Initiative (WAI). http://www.w3.org/WAI/ (2009-03-20).

Recibido: 2009-03-30. Revisado: 2009-04-11. Aceptado: 2009-04-20

Scire. $15: 2$ (jul.-dic. 2009) 121-139. ISSN 1135-3716. 